\title{
The Leading Chinese Internet Companies Competition for the Dominant Design of Mobile Payment Instruments
}

\author{
Yinliping \\ Yinliping6@hotmail.com \\ College of Business Administration, \\ Capital University of Economics and Business., \\ Zhangjiaolukou 121\# , Fengtai, 100070, Beijing ,China.
}

\begin{abstract}
Keywords: dominant design,competition,mobile payment
\end{abstract}
\begin{abstract}
With the development of mobile internet terminal, a large number of the electronic transaction activities of PC end began to migrate to the mobile terminal,mobile payment instruments as the basis of mobile Internet transaction activities become the new battlefield of dominant design competition. This paper studies two China Internet giants' advantages and disadvantagesin in the dominant design competition ,design principle and payment scenarios of two kinds of payment means are compared and the corresponding conclusion is drawn.
\end{abstract}

\section{Introduction}

This article reveals the process mechanism of a Chinese Internet company in the passive transition from Internet business to the mobile Internet business.Using an acquisition as a way of path creation, firms must go through an process of cognitive change.Only realizing the essence of the new business model changes, A acquiring firm clearly determines the acquired business and the value of the acquired business. Second, the paper argues that the value of the acquired company is not just including financial value, but also including its strategic value and other factors. Finally, this paper analyzes the pros and cons of the acquisition as a way of path creation.

IResearch Data[ ]show that in 2013 China third-party mobile payment market transaction amounted to 1.21974 trillion yuan, representing growth of $707 \%$. Among them, transfers, payments and other personal applications become a major source of transaction size, mobile online shopping is no longer the main scene of supporting the development of the industry . IResearch believes that along with the development of mobile payment technology, the off-line market will become the core of the battlefield that Internet giant, acquirers, operators, banks and other multi-party compete in. With the online market matures, the Internet payment companies will focus on reverse O2O market from off-line to on-line, in order to attain offline market breakthrough.

As the first entry of connection off- line market with on-line market, mobile payments become the new competition focus of Chinese Internet giants recently. Tencent' micro-message pay with Alibaba' Alipay launched subsidy money “war “. Tencent with Didi taxi software for pushing micro-message pay, passengers and drivers award for\$ 10 every order subsequently, AliBaba "ho throw" 500 million yuan, joining with quick taxi software, using the PayPal payment the driver on the spot will get 15 yuan reward, passengers on the spot relief 10 yuan fare. Both sides are willing to subsidize drivers and passengers,is their competitive intent exactly what? Who can win the final victory in this competition? This paper attempts to use disruptive innovation theory to analyze these competing phenomena.

\section{Literature Review}

Schillng [1] proposed the dominant design formation of innovative products and services depends on if they bring value to their customers in three aspects. The first is whether the value of the technical performance and effectiveness of the product itself is beyond the alternative products and competitors' products. Technical efficiency value including purchase, delivery, use, consumables, maintenance and disposal of these products in the use cycle, they is whether simple, convenient, entertainment,environmental protection. However, the technological effectiveness of innovative products with high value does not necessarily become the dominant design on the market. The 
second is the value of installed users scale . Installed user base increase the value of every user of innovative products. The compatibility of large scale product users is better, service and maintenance have economies of scale, and so on . The third is the value of Ancillary products. The most innovative products is only the basic products, when using the innovative products users need a great deal of ancillary products. Only the total value of these factors of an innovative product is greater than old products or competitor'products, it will become the dominant design product. Schillng [1] think that innovative products that is the relatively lower in technical efficiency may also become the market leader due to the greater total value of innovative products by the greater installation base and more Ancillary products. Dominant design competition that is not only the competition between the new products, but also the competition between the old products and new products. Christensen [2] has elaborated why new products could replace old products. New products firstly meet the consumer market is not meet demand by old products.In point of view of product,The new product has new value dimension old products not have and ignore the value dimension , so following a new product market emerging, new product foothold in the market. With the main value dimensions old products valued in a new product value dimensions is improved,new products will replace old products and become the dominant design. Tripsas (1997) [3] think when innovative products replace old products, the leader of the old dominant design product will not stand still , they can cross the chasm of creative destruction through complementary assets. The three scholars'research from different angles improve the formation mechanism of the innovative product dominant design. By the combination of these theories, we can analyze what the final result of the dominant design competition might be in reality.

\section{Comparision of Alipay and micro- letters payment}

Comparing the platforms two payment instruments based on. Alipay is a third-party payment instruments based on C toC platform Taobao and B to C platform Lynx on PC. Alipay belongs to Alibaba Groups. Setting up Alipay is to solve the confidence problems of China's online shopping market. After the payment issue is solved ,the development of Taobao show explosive growth trend. In 2004 , Taobao transaction volume rose rapidly to 10 billion and reached 80 billion yuan in 2005. Such growth has continued. As of November 30, 2012 , trading volume of Taobao and Lynx break one trillion yuan. From 20 million yuan to 1 trillion yuan, Taobao and Lynx increased five -fold in a decade. According to the National Bureau of Statistics, China' 2011 GDP is 47.2 trillion , compared with it, Taobao and Lynx turnover about 2\% GDP[4]. Total retail sales nationwide is 18.39 trillion, Taobao and Lynx turnover equivalent to $5.4 \%$ of total retail sales[4] . Dependent on China 's two largest e-commerce platform Taobao and Lynx , Alipay is dominant PC-payment firm on China's e-commerce market. After the rise of the mobile Internet, Alibaba launched a mobile payment tool APP Alipay wallet, it has the advantage over the other mobile payment. In the years Alipay on the PC side has already accumulated a huge online buyers resources and sellers resources on Taobao and Lynx , these resources through Alipay wallet can be directly translated to the mobile side , but the design principle of Alipay wallet is not very different from Alipay of the PC side.

Micro-channel payment is a mobile payment tool launched by China 's three major Internet company Tencent. Relying on social mobile instant messaging platform-----Micro-Channel. Micro-Channel is China 's largest mobile social platform and have reached 600 million users in 2013 , over 10 billion proposed in 2014 , the penetration rate of micro-channel in China'smart phone is close to $100 \%$ [5]. Relying on micro-channel platform, micro-channel payment quickly became a rising star of payment instruments. Late last year, Tencent by micro-channel platform embedded by the taxi software Didi, the taxi software Didi embedded by micro-channel payments and two-way subsidies policy make the majority micro-channel users experience the micro-channel payment function at first time. Earlier this year, Tencent continued to launch a micro-channel "red envelope" feature, users in a red envelope function in the first select the number of Red Envelope and the total amount of payment, and then distributed through the micro-channel payment to the micro-channel group , group members click on the red envelope, will be able to get a randomly assigned amount, compared to the " one to one" way to send a red envelope, this is a stronger participation. Red envelope quickly became popular after the "red " feature launched . "Red envelope" feature is sought after by users primarily for three reasons[6] : First, the Spring Festival approaching, the user have the psychological needs of giving envelopes; Second, 'Red Envelope" feature emphasis on micro-channel relationships and social attributes; Third "grab red envelope" 
process designed increase the entertainment and improve participation. Micro letter " red envelopes " can guide a large number of micro-channel clients to bind bank cards, " red envelopes " function due to the good mix of social elements and payment, have a great help for increasing in micro-channel user and micro-channel payment users, with " New Year red envelopes " and before bundled with the taxi software Didi , the users of micro-channel paymeny has more than the Alipay users, micro-channel using the advantages of social property " counter-attack " Alipay, powerful offensive has caused market wide attention.

The differences in design principle of two payment tools. Alipay is a trading account associated with a bank account. After a transactions on Taobao and Lynxpaid, buyers confirm goods, the buyer's Alipayl account will transfer money to the seller's Alipay account, Alipay has a secured transactions role in the trading platform. Since the interval between the transaction reached and Money to pay , Alipay account deposited a large amount of customer funds when buyers and sellers of real Alipay account transfers and their bank account transfers. Go with the flow, Alipay became a managers of resident fund between customers and merchants. To this end, Taobao developed treasure account for the use of these funds, treasure account can be used directly for payment transactions, and fund in treasure account is different from fund in Alipay account,can be paid interest which is twice the interest of bank account, and buyer' treasure account and anlipay account can transfer to each other . Compared Alipay, Alipay wallet though to some extent simplifies the payment process, but because of the identity of the fund managers, it tend to stay the user' funds in their own account as far as possible, this feature is very evident on treasure account in this product. It is a powerful characteristic of " Lynx + Taobao +Alipay+ treasure" , but it determines the Alipay weakness: the payment process can not be completely simplified. Compared Alipay wallet, micro-channel payments process are further simplifying on the basis of the quick payment, and third party payment platform also be simplified out, let you back the direct payment process by bank card to minimum payment time. Compared Alipay and Alipay wallet management in stock funds and the flow of funds, micro-channel specialize in flow of funds, so the micro-channel paymet have nostalgia for stock funds. Only bank card logo, there is no concept of treasure account, on the micro-letter page, does not exist other payment account outside of Micro-Channel, and will not advise you to use treasure account to purchase financial products. This will cut all things outside mobile payment, in fact, micro-channel paymet is to restore the true nature of payments. But due to dual function, Alipay'payment process designed is very complex, many users can not tell the difference between Taobao' account and Alipay 'account, but few people can remember clearly Alipay login password. After the micro-channel payment cut off those excess baggage, a full-featured Alipay walletis will no way to imitate it. Because the micro-channel payment only need to secure the connection of micro-channel and bank cards, but Alipay wallet not only secure the connection but also ensure the safety of the account funds -the two tasks would not be a difficult level, the strength and experience can not make up the gap. Micro-channel payment need not shake Alipay' market share, only maintaining their customer experience advantage in the payment process it can result in continued pressure on Alipay, and Alipay precisely and can not abandon stock foundation to fight traffic with Micro-Channel payment .

The comparison of payment scenarios of two kinds of mobile payment. Previously payment is only offline, since the rise of the Internet it moves to online, there with the development of mobile Internet mobile terminalit it move to the offline again, the boundaries between online payment and offline payment is blurring, and the integration continues to accelerate. Therefore, for Alibaba and Tencent, the expansion of mobile paymentn market has become the focus of competition. From taxi software are subsidized Bilaterally, we can see the importance of the competition. If the next Alibaba's Alipay wallet fail to develop mobile online payment market, its online payment tool Alipay(PC) may be lost dominance. Tencent can cut into the online payment market by Micro-channel payment alternative to Alipay utilizing its strong social attributes. If Tencent offline payment marketing is a failure, Micro-channel will have no opportunity to enter online payment market and Internet financial markets. Thus, the expansion of mobile payment scenes has become a key competitive core.

April 2013 Alibaba bought Sina’ Weibo 18\% of the shares at \$ 586 million , the two sides will carry out in-depth cooperation in the user account exchange, data exchange, online payment, online 
marketing and other fields. Through the acquisition, Alibaba trying to connect Alipay wallet with mobile social networking tools to make up for Alipay wallet social property defects, and develop the so-called socialized electric commerce. March 2014, Ali Group to purchase 9.9\% share of Intime business and convertible bonds at 5.37 billion Hong Kong dollars. After this strategic investment, Ali Group and Intime business will be fully open membership system, payment system, and $t$ will achieve the docking of the two business systems. On this basis, the two sides will build a foundation system to get through online and offline business, to achieve seamlessly connection between commodity trading online and offline, membership marketing and membership services. This system will be open to the whole society for all offline major business Group, the retail brand and retailer services. Through the acquisition ,Alibaba will moves offline payment into online payments by launching a smartphone "face pay" feature. February 2014, Alibaba announced it will acquire $72 \%$ of shares of High German company at $\$ 1.1$ billion cash. After the completion of the transaction, The two sides will cooperate on map search, product commercialization, data sharing, in the field of cloud computing. In the mobile Internet era, the map's role as the entrance is constantly being strengthened. Mobile and location information are closely related, mobile maps can become not only a series of basic necessities of life service entrance,and can also be derived from a number of mobile applications to become a variety of $\mathrm{O} 2 \mathrm{O}$ application platforms based on the association between the user position and offline merchants ,thus Alipay wallet service can be provided on these application platforms. Alibaba is try to embed its mobile payment instruments in the mobile terminal applications platforms and APP.After the company acquired the video site Youku, April 2014, Alibaba and China Media entered into a strategic cooperation, the two sides will jointly participate in original content, video messaging, games, music, education, cloud computing, big data and other areas, and jointly develop the cultural media industry chain downstream. China Media is one of seven domestic television license square internet, Alibaba will extended mobile payment to a home digital network TV platform through the acquisition.Alibaba'expanding mobile payment scenarios can be described as everywhere.

Tencent's mobile payment scenarios is also expanding in full swing. February 2014, Tencent acquired a 20\% stake in the Public Comments site that is a catering dining buy platform. Micro letter embedded "Today cuisine" ------ Public Comment catering buy services. Number of Public Comment active users is over 90 million monthly, and the number of businesses indexed is over 8 million. After the transaction is completed, Tencent will squeeze Alipay OTO line payment market. Micro-channel can expand payment within App , and lead the entire offline consumer end payments market(food line). March 2014, Tencent announced, it will be \$ 214 million to acquire $15 \%$ stake in Jingdong. After the transaction, Tencent will provide support Jingdong with micro-channel and mobile QQ client entry level positions and other major platforms. The two sides will cooperate in the online payment service. The industry generally believe that Tencent is China's stake in the electricity supplier industry Jingdong landmark merger transaction, the industry will have a profound impact on the pattern. Tencent has an advantage in terms of mobile Internet, Jingdong self logistics and electricity supplier strong physical category. For Jingdong, although already very strong in the electric business platform, but mobile and social basically no entrance, access to micro-channel and mobile QQ client the entrance, will generate huge boost to their business. Accordingly, for Tencent, the cooperation with Jingdong can promote the development of micro-channel payments, the Web client micro-channel sweep yards payment will extended to the end of the PC and payment scenes of mobile e-commerce platform. In addition, micro-channel payment services can be extended also to offline payment through public platforms. Once the micro-channel release functional interface to the merchant's public number, the potential of micro-channel payment will quickly broke out. Finally, Tencent is develop offline payment with a scan two-dimensional code. Users can scan the two-dimensional code of product to buy and achieve payment. With the development of mobile Internet, this scenario will become more common. This part of the payment market is likely to impact UnionPay cards, credit card and other consumer areas, more transaction are transferred to the micro-channel payment. This market is bigger than online, more vast, more imaginative $\mathrm{O} 2 \mathrm{O}$ market.

\section{Discussion and conclusion}

Mobile payment is the future direction of payments market. In the mobile environment, which kind of payment tool can create value for consumers, which mobile payment methods are more likely to 
become the dominance design in the market. As a mobile payment tool, what doesc consumers value mobile payment performance? Firstly, the security of mobile payment security is the most important. Mobile payment is payment instruments associated with bank cards, credit cards, if payment information once leaked, users will suffer from large losses.In terms of payment security, Technical support of Alipay wallet is stronger. However, although technically micro-channel is at a disadvantage , but by paying insurance claims Tencent overcome this security problem, from a consumer, the difference between the two mobile payment security is not large. Secondly, as mobile payments the key is whether shorten original payment process and time. Since the micro-channel is paid within APP, as long as the first binding bank cards, afterward , the payment is very fast,and this binding can be done directly on the phone . Micro-channel cut into the mobile payment market from those who do not have Alipay account. However, Alipay need apply for bank counter to designate a Alipayl account associated with bank card before you can operate on PC side. Compared to Alipay, micro-channel payment advantage is obvious.After the introduction of micro-channel payment, Alibaba launched a mobile payment - Alipay wallet to deal with this challenge, Alipay wallet is similar to Micro-channel payment, Alipay wallet is an APP associated with a bank card. From the perspective of payment, Alipay wallet has one middle step in the payment, user need to put the money into the Alipayl wallet account from a bank card or Alipay balance for payment. But Micro-channel payment is without this link, it is direct payments on no time,and Alipay wallet taking up extra phone memory , which may be one of the mobile payment instruments defects in middle and low end mobile phone. Thirdly, the richness of the payment scenes. From the development direction, the width and intensity of both existing payment scenario, the two sides can be said to be evenly matched. Alipay wallet though a bit complicated in the payment process, but the payment scenes of Alipay wallet is not inferior to the micro-channel payment scenes expanded in mobile payment fields, in the competitiveness of taxi software market, there is no winner,there have formed a Hutch side by side situation. Alibaba addition to payment of market phone Taobao and Lynx on almost all payments associated with close major mobile terminals and mobile APP has paid cooperate in the field next online marketing Alibaba is also very aggressive involved very and more, including the payment of a physical store , the future of online pay television market, securities market to pay the phone side , etc., in the future to expand the market for mobile payments and imagination on Alibaba slightly better. Micro-channel expansion due to the payment of the payment scenarios rely on social attributes , and its development potential is immeasurable. Once the number of its public opening, the huge market of mobile payments instantly micro-channel can be formed . The above analysis, the future of mobile payments market will duopoly competition. As the mobile market is large enough, there will be the possibility of the coexistence of the two largest dominant design on the market in the future. Like the smart phone operating system market, like, IOS Mobile and Android phones coexist.

\section{Acknowledgements}

This paper has been funded by General Program projects (sm201210038009) of Beijing Municipal Education Commission.

\section{References}

[1] M. A. Schilling:Strategic Management of Technological Innovation,Chinese Version,Tsinghua. University press,Beijing 2005

[2] C.M.Christensen:the Innovators’ Dilemma: When New Technologies Cause Great Firms to Fail, Chinese Version, CITIC Publishing House,Beijing 2010

[3] M.Tripsas : Unraveling the process of creative destruction: complementary assets and incumbent survival in the typesetter industry,Strategic Management Journal, Summer Special Issue 18(1997),pp. 119-142.

[4] http://money.163.com/12/1204/08/8HS9QVMR00253B0H_all.html

[5] Luo Chao: Micro message, standing on the threshold of the 600 million users, http://www.huxiu.com/article/21947/1.html

[6] http://www.cnblogs.com/aigongsi/p/3448890.html 